\title{
Molecular Characterization of Fenugreek (Trigonella foenum-graecum L.) Genotypes Using Rapd Markers
}

\author{
N.C. Mamatha*, S.K. Tehlan, M. Srikanth, M.K. Shivaprasad and P. Karthik Reddy \\ Department of Vegetable Science, CCS Haryana Agricultural University, Hisar-125 004, India \\ *Corresponding author
}

\section{A B S T R A C T}

The study was conducted to reveal the genetic diversity among 48 fenugreek genotypes using thirty Random Amplified Polymorphic DNA (RAPD) markers among which, nineteen primers gave good amplification and revealed a total of 119 polymorphic bands with an average of 6.26 bands per primer. The percentage of polymorphism ranged from 50.00 to 91.66 per cent with an average of $79.21 \%$ polymorphism per primer. Primer OPP-8 revealed the highest polymorphism (91.66\%), whereas the primer OPC-2 exhibited the lowest polymorphism (50.00\%). The polymorphic information content (PIC) value ranged from 0.66 to 0.90 . Highest PIC value was obtained in primers OPP- 8 followed by OPP-9, OPH-5, OPF-13, OPJ-18, OPB-5, OPC-17, OPAB-2, OPH-4 and OPN-2 and the lowest PIC value was obtained in OPC-19 followed by OPC-11 and OPG-11.UPGMA dendrogram presented into 10 clusters at 0.75 similarity coefficient. The similarity coefficient ranging from 0.59 to 1.00 . Principal component analysis confirmed the results of UPGMA. The genotypes which are falling in different groups indicate the presence of genetic diversity between the members of different clusters. Crossing can be made between the members of different clusters for further crop improvement, as they are genetically diverse.

\section{Introduction}

The genus Trigonella is one of the largest genera of the tribe Trifoliatae in the family Fabaceae (Balodi et al., 1991). It is a flowering annual, with autogamous white flowers occasionally visited by insects and is originated in the eastern shores of Mediterranean region. Fenugreek is widely cultivated in India, Egypt, Ethiopia, Morocco and occasionally in England (Polhil et al., 1981). It is widely cultivated in the tropical and subtropical regions of India. Fenugreek is rich in minerals, protein, vitamin $\mathrm{A}$ and $\mathrm{C}$. For any crop improvement program the basic requirement is availability of germplasm with wide variability. Germplasm pool is an important source of variability for developing new cultivars having good economic traits. Hence, assessment of genetic divergence in fenugreek germplasm is important for long term crop improvement programme.

Genetic diversity can be identified using morphological, biochemical and molecular markers. But, the morphology of plant is influenced by environment and developmental stages of crop, in this context 
the molecular markers act as best tool for evaluating genetic diversity of crop germplasm which enables in understanding the genetic relationship among fenugreek genotypes.

Random Amplified Polymorphic DNA (RAPD) marker is the popular and widely used dominant marker which uses ten base primer to amplify the random portion of genome (Williams et al., 1990) and it does not need prior information of target genome.
1. RajendraKranti
13. HM-208
2. RM-194
14. HМ-221
3. $\mathrm{RM}-188$
15. HМ-239-1
4. GM-1
16. HM-242
5. GM-2
17. НM-246
6. JFG-235
18. HM-257
7. JFG-266
19. HM-258-1
8. HM-57
20. HM-273
9. HM-65
21. HM-281
10. HM-103
22. HM-291
11. HM-114
23. HM-307
12. HM-205
24. HM-332

\section{Genomic DNA isolation}

Genomic DNA was isolated from young leaves of 48 fenugreek genotypes following CTAB (Cetyltrimethyl ammonium bromide) extraction method as given by Murray and Thompson (1980) and modified by SaghaiMaroof et al., (1984).

\section{Qualitative and quantitative estimation of} DNA

The quality and quantity of isolated genomic DNA will be estimated by UV Spectrophotometer (A260/A280 absorbance)

\section{Materials and Methods}

\section{Plant material}

Forty eight fenugreek genotypes were collected from different parts of the country i.e., Andhra Pradesh, Bihar, Delhi, Gujarat, Haryana, Rajasthan and Uttar Pradesh. The seeds were sown in pro trays under polyhouse and young leaves were collected for DNA extraction. List of 48 genotypes used for molecular characterization are as follows:

$\begin{array}{ll}\text { 25. HM-343 } & \text { 37. HM-528 } \\ \text { 26. HM-346 } & \text { 38. HM-536 } \\ \text { 27. HM-348 } & \text { 39. HM-548 } \\ \text { 28. HM-355 } & \text { 40. HM-555 } \\ \text { 29. HM-359 } & \text { 41. PEB-1 } \\ \text { 30. HM-444 } & \text { 42. LFC-93 } \\ \text { 31. HM-502 } & \text { 43. AFG-5 } \\ \text { 32. HM-507 } & \text { 44. AFG-6 } \\ \text { 33. HM-509 } & \text { 45. UM-202 } \\ \text { 34. HM-517 } & \text { 46. UM-354 } \\ \text { 35. HM-519 } & \text { 47. NDM-69 } \\ \text { 36. HM-526 } & \text { 48. NDM-72 }\end{array}$

and the DNA was also tested by submerged horizontal agarose $(0.8 \%)$ gel electrophoresis.

\section{Polymerase chain reaction (PCR) amplification}

Thirty RAPD primers were used for divergence studies (Table 1). PCR amplification was carried out in touch down Q-thermo cycler. The PCR reactions were carried out in $23.5 \mu$ l of reaction mixture containing $13.5 \mu \mathrm{l}$ of sterile distilled water, $2.5 \mu \mathrm{l}(10 \mathrm{x}$ colorless buffer) reaction buffer, $2 \mu l \quad$ dNTP $\quad(500 \mu l \quad$ dNTP of concentation $10 \mathrm{mM}+500 \mu \mathrm{l}$ of sterile 
distilled water), $2 \mu \mathrm{l}$ of $\mathrm{Mgcl}_{2}(25 \mathrm{Mm}), 2 \mu \mathrm{l}$ of primer $(10 \mu \mathrm{l}$ primer $+90 \mu \mathrm{l}$ of nuclear free water), $1 \mu l$ template DNA and $0.5 \mu 1$ of Taq DNA polymerase $(5 \mathrm{U} / \mu \mathrm{l})$. These were added into PCR tube in same sequence as above. In PCR amplification program for initial denaturation $4 \mathrm{~min}$ at $94^{\circ} \mathrm{C}$, followed by 36 cycles of $1 \mathrm{~min}$ at $94^{\circ} \mathrm{C}$ for denaturation, annealing temperature varied according to primer, $72^{0} \mathrm{C}$ for $2 \mathrm{~min}$ and for final extension $72^{0} \mathrm{C}$ for $8 \mathrm{~min}$ is followed. Amplified DNA fragments were resolved by submerged horizontal agarose gel electrophoresis in $1.5 \%$ (w/v) agarose gel and visualized by staining with ethidium bromide. Agarose solution was prepared in $1 \mathrm{X}$ TBE and ethidium bromide $(10 \mathrm{mg} / \mathrm{ml})$ was added in the gel at a concentration of $3 \mu \mathrm{l}$ per $100 \mathrm{ml}$ of gel and then mixed gently. It was poured in gel casting tray with appropriate comb with required well number and size. PCR products were mixed with loading dye and loaded into wells. The gel was run at the voltage of 100 watts for 1 hour and is seen under UV light for presence of bands. And photo was taken in gel documentation system.

\section{Allele scoring}

The total number of bands within each line and number of polymorphic bands were noted. Each DNA fragment amplified by a given primer was considered as a unit character and the RAPD amplification profiles were scored visually, based on presence (taken as 1) or absence (taken as 0 ) of bands for each genotype. Only clear and unambiguous bands were scored. The size of amplified bands was determined based on its migration relative to standard molecular weight markers.

\section{Cluster analysis}

The scored band data was subjected to statistical analysis using the computer programme NTSYS (version 2.02). The resultant similarity matrix was used to generate a tree by UPGMA. Dendrogram was constructed by using distance matrix in SAHN sub-programme of NTSYS-pc software by the Unweighted Pair-Group Method with Arithmetic Average (UPGMA) algorithm. Principal Component Analysis (PCA) was done to construct 2 and 3 dimensional diagrams.

\section{Results and Discussion}

\section{Primer selection and polymorphism exhibited}

The analysis of the prescreened data using 48 fenugreek genotypes and thirty RAPD primers showed that nineteen primers amplified unambiguous, readable and reproducible polymorphic bands. A total of 146 amplification products were produced from the selected 19 primers out of which 119 bands were polymorphic. The number of bands varied from 3 to 12 and the size ranged from 150 to $1500 \mathrm{bp}$. The highest number of bands (12) obtained in primer OPP-8, while the lowest number of bands (3) was observed with primer OPC-19 with an average of 7.68 bands per primer. Highest number of polymorphic bands was observed in primer OPP-8 and the lowest number of polymorphic bands was observed in primer OPC-19 and OPC-2. The percentage of polymorphism ranged from 50.00 to 91.66 per cent with an average of $79.21 \%$ polymorphism per primer. Primer OPP-8 revealed the highest polymorphism $(91.66 \%)$, whereas the primer OPC-2 exhibited the lowest polymorphism $(50.00 \%)$. The polymorphic information content (PIC) value ranged from 0.66 to 0.90 . Highest PIC value was obtained in primers OPP-8 followed by OPP-9, OPH-5, OPF-13, OPJ-18, OPB-5, OPC-17, OPAB-2, OPH-4 and OPN-2 and the lowest PIC value was obtained in OPC-19 followed by OPC-11 and OPG-11 (Table 2). 
It clearly indicated that the primers used in the present study contributed moderate to high as far as PIC value is concerned. Their relative contribution is assessed accordingly and must be utilized in the light of PIC value. So, the primers OPP-08, OPP-09, OPH-05, OPF-13, OPJ-18, OPB-05, OPC-17, OPAB02 , $\mathrm{OPH}-04$ and $\mathrm{OPN}-02$ proved best to assess the diversity in fenugreek. Similar results were reported by Dangi et al., (2004),
Sundaram et al., (2011), Choudhary et al., (2013) and Tomar et al., (2014). Since there was no relationship between the total number of bands generated by a primer and amount of polymorphism produced, we cannot assign the ranking to a particular primer simply based upon the total number of bands it produces. In literature there is no report indicating the existence of any such correlation.

Table.1 RAPD primers used in present investigation

\begin{tabular}{|c|c|c|c|c|c|c|c|}
\hline $\begin{array}{l}\text { S. } \\
\text { No. }\end{array}$ & $\begin{array}{c}\text { Primer } \\
\text { code }\end{array}$ & $\begin{array}{c}\text { Primer } \\
\text { sequence }\end{array}$ & Length & $\begin{array}{l}\text { S. } \\
\text { No. }\end{array}$ & $\begin{array}{c}\text { Primer } \\
\text { code }\end{array}$ & $\begin{array}{c}\text { Primer } \\
\text { sequence }\end{array}$ & Length \\
\hline 1 & OPB-05 & TGCGCCCTTC & 10 & 16 & OPH-06 & ACGCATCGCA & 10 \\
\hline 2 & OPC-02 & GTGAGGCGTC & 10 & 17 & OPJ-02 & CCCGTTGGGA & 10 \\
\hline 3 & OPC-05 & GATGACCGCC & 10 & 18 & OPJ-04 & CCGAACACGG & 10 \\
\hline 4 & OPC-08 & TGGACCGGTG & 10 & 19 & OPJ-06 & TCGTTCCGCA & 10 \\
\hline 5 & OPC-09 & CTCACCGTCC & 10 & 20 & OPJ-10 & AAGCCCGAGG & 10 \\
\hline 6 & OPC-11 & AAAGCTGCGG & 10 & 21 & OPJ-18 & TGGTCGCAGA & 10 \\
\hline 7 & OPC-17 & TTCCCCCCAG & 10 & 22 & OPJ-20 & AAGCGGCCTC & 10 \\
\hline 8 & OPC-19 & GTTGCCAGCC & 10 & 23 & OPN-02 & ACCAGGGGCA & 10 \\
\hline 9 & OPF-13 & GGCTGCAGAA & 10 & 24 & OPP-08 & ACATCGCCCA & 10 \\
\hline 10 & OPF-14 & TGCTGCAGGT & 10 & 25 & OPP-09 & GTGGTCCGCA & 10 \\
\hline 11 & OPF-18 & TTCCCGGGTT & 10 & 26 & OPAB-01 & CCGTCGGTAG & 10 \\
\hline 12 & OPG-07 & GAACCTGCGG & 10 & 27 & OPAB-02 & GGAAACCCCT & 10 \\
\hline 13 & OPG-11 & TGCCCGTCGT & 10 & 28 & OPAB-03 & TGGCGCACAC & 10 \\
\hline 14 & OPH-04 & GGAAGTCGCC & 10 & 29 & OPAB-04 & GGCACGCGTT & 10 \\
\hline 15 & OPH-05 & AGTCGTCCCC & 10 & 30 & OPAB-06 & GTGGCTTGGA & 10 \\
\hline
\end{tabular}


Table.2 Polymorphism exhibited by RAPD primers in fenugreek genotypes

\begin{tabular}{|c|c|c|c|c|c|c|c|c|c|}
\hline $\begin{array}{l}\text { Sr. } \\
\text { No. }\end{array}$ & $\begin{array}{l}\text { Primer } \\
\text { code }\end{array}$ & Primer sequence & Length & $\begin{array}{c}\text { Total } \\
\text { number } \\
\text { of bands }\end{array}$ & $\begin{array}{c}\text { Number of } \\
\text { monomorphic } \\
\text { bands }\end{array}$ & $\begin{array}{l}\text { Number of } \\
\text { polymorphic } \\
\text { bands }\end{array}$ & $\begin{array}{c}\text { Polymorphism } \\
(\%)\end{array}$ & PIC & $\begin{array}{c}\text { Molecular } \\
\text { weight range } \\
\text { (bp) }\end{array}$ \\
\hline 1. & OPAB-2 & GGAAACCCCT & 10 & 9 & 1 & 8 & 88.88 & 0.86 & $350-1000$ \\
\hline 2. & OPB-5 & TGCGCCCTTC & 10 & 10 & 1 & 9 & 90.00 & 0.87 & $200-1000$ \\
\hline 3. & OPF-13 & GGCTGCAGAA & 10 & 9 & 3 & 6 & 66.66 & 0.88 & $150-1000$ \\
\hline 4. & OPF-14 & TGCTGCAGGT & 10 & 10 & 2 & 8 & 80.00 & 0.80 & $200-1200$ \\
\hline 5. & OPH-5 & AGTCGTCCCC & 10 & 10 & 1 & 9 & 90.00 & 0.89 & $200-1000$ \\
\hline 6. & OPH-4 & GGAAGTCGCC & 10 & 10 & 2 & 8 & 80.00 & 0.85 & $300-1000$ \\
\hline 7. & OPJ-6 & TCGTTCCGCA & 10 & 7 & 2 & 5 & 71.42 & 0.82 & $400-1000$ \\
\hline 8. & OPJ-10 & AAGCCCGAGG & 10 & 7 & 1 & 6 & 85.70 & 0.83 & $200-800$ \\
\hline 9. & OPC-17 & TTCCCCCCAG & 10 & 6 & 1 & 5 & 83.33 & 0.87 & $500-1500$ \\
\hline 10. & OPJ-18 & TGGTCGCAGA & 10 & 11 & 2 & 9 & 81.81 & 0.88 & $400-1500$ \\
\hline 11. & OPJ-20 & AAGCGGCCTC & 10 & 8 & 1 & 7 & 87.50 & 0.85 & $350-1000$ \\
\hline 12. & OPP-8 & ACATCGCCCA & 10 & 12 & 1 & 11 & 91.66 & 0.90 & $300-1500$ \\
\hline 13. & OPP-9 & GTGGTCCGCA & 10 & 10 & 1 & 9 & 90.00 & 0.89 & $300-1500$ \\
\hline 14. & OPC-11 & AAAGCTGCGG & 10 & 4 & 1 & 3 & 75.00 & 0.67 & $500-1000$ \\
\hline 15. & OPC-19 & GTTGCCAGCC & 10 & 3 & 1 & 2 & 66.66 & 0.66 & $900-1000$ \\
\hline 16. & OPC-2 & GTGAGGCGTC & 10 & 4 & 2 & 2 & 50.00 & 0.74 & $400-900$ \\
\hline 17. & OPG-11 & TGCCCGTCGT & 10 & 4 & 1 & 3 & 75.00 & 0.67 & $400-700$ \\
\hline 18. & OPH-6 & ACGCATCGCA & 10 & 5 & 1 & 4 & 80.00 & 0.77 & $600-1200$ \\
\hline 19. & OPN-2 & ACCAGGGGCA & 10 & 7 & 2 & 5 & 71.42 & 0.85 & $200-1000$ \\
\hline \multicolumn{4}{|c|}{ Total } & 146 & 27 & 119 & & & \\
\hline \multicolumn{4}{|c|}{ Average } & 7.68 & 1.42 & 6.26 & 79.21 & & \\
\hline
\end{tabular}


Table.3 Clustering of 48 fenugreek genotypes using RAPD at 0.75 similarity coefficient

\begin{tabular}{|c|c|l|}
\hline Clusters & $\begin{array}{c}\text { Number of } \\
\text { genotypes }\end{array}$ & \multicolumn{1}{|c|}{ Genotypes } \\
\hline I & 1 & PEB-1. \\
\hline II & 2 & UM-354, UM-202. \\
\hline III & 3 & HM-307, HM-273, HM-507. \\
\hline IV & 5 & HM-65, HM-208, HM-555, HM-258-1, HM-257. \\
\hline V & 3 & HM-548, HM-517, HM114. \\
\hline VI & 4 & HM-343, HM-348, HM-355, HM-239-1. \\
\hline VII & 1 & RajendraKranti. \\
\hline VIII & 21 & $\begin{array}{l}\text { LFC-93, HM-528, HM-242, HM-205, NDM-69, NDM-72, HM-444, JFG-235, HM-502, HM-359, } \\
\text { HM-526, AFG-6, JFG-266, AFG-5, HM-332, HM-103, HM-346, HM-536, HM-221, GM-1, GM-2. }\end{array}$ \\
\hline IX & 2 & HM-291, HM-281. \\
\hline X & 6 & RM-188, HM-509, RM-194, HM-246, HM-57, HM-519. \\
\hline
\end{tabular}


Fig.1 Dendrogram generated using RAPD markers in 48 fenugreek genotypes

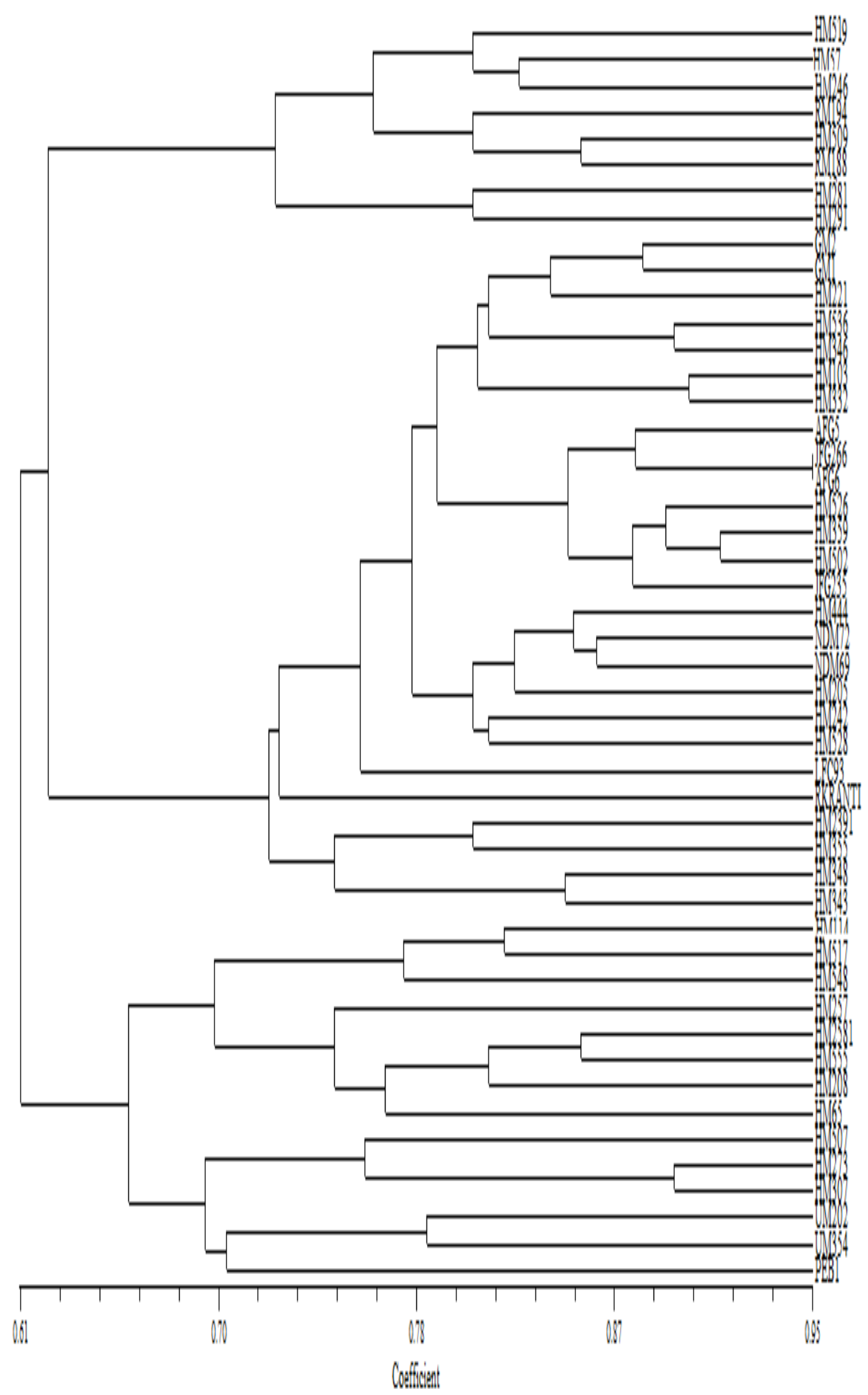


Fig.2 Two dimensional PCA scaling of 48 fenugreek genotypes using RAPD

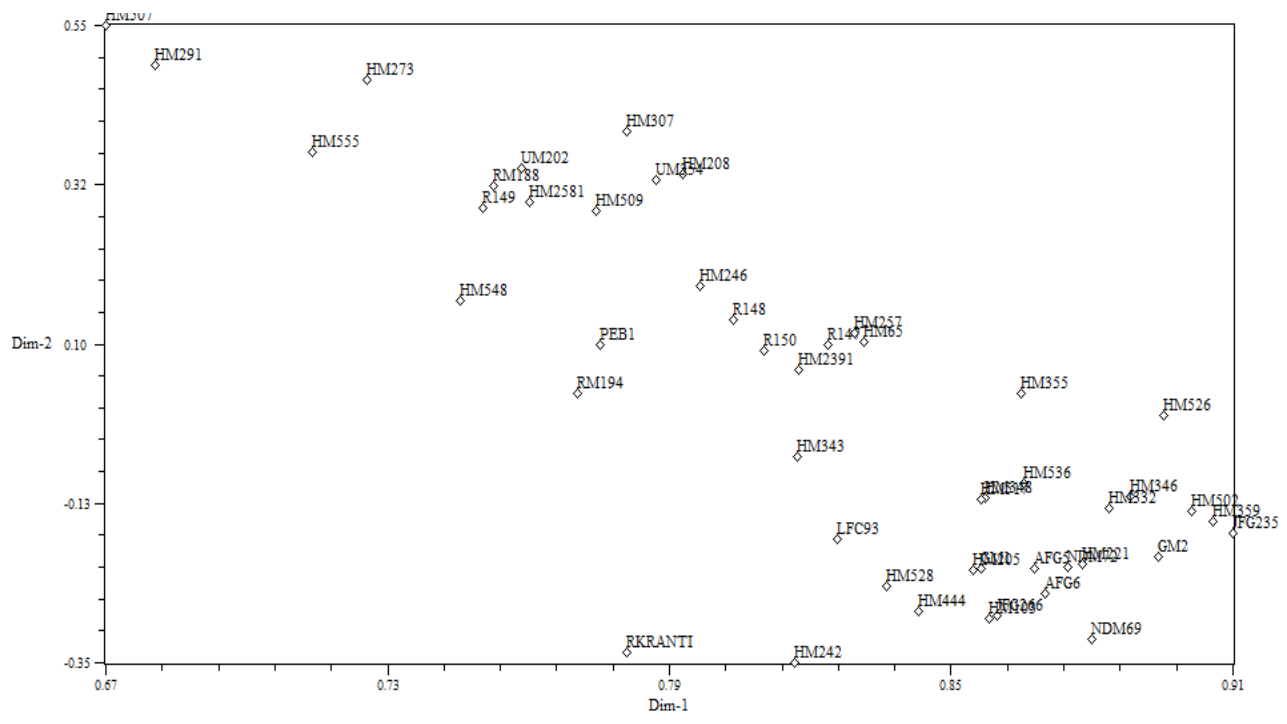

Fig.3 Three dimensional PCA scaling of 48 fenugreek genotypes using RAPD

\section{Cluster analysis}

Molecular data obtained using 19 RAPD primers was used to construct dendrogram which, divided the fenugreek genotypes into 10 clusters at 0.75 similarity co-efficient (Table 3). The similarity co-efficient ranged from 0.61 to 0.95 (Fig. 1). The two dimensional as well as three dimensional diagrams also formed using same results as of dendrogram and are presented in figures 2 and

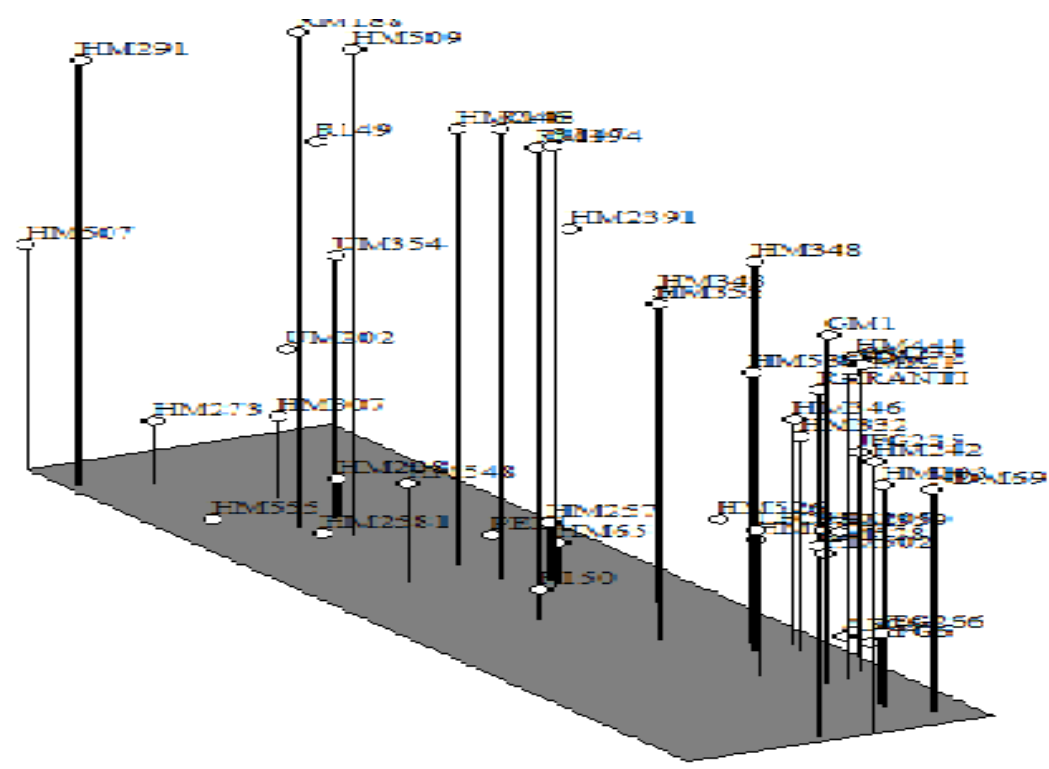

3 respectively. The genotypes from one region were grouped together in some cases while they were placed in different clusters in certain cases. The clusters containing genotypes from same region maybe due to their pedigree relationship or they may be selected from same breeding population.

The measures of relative genetic distances among varieties of fenugreek did not completely correlate with the geographical 
distances of places of their development. And the genotypes which are falling in different groups indicate the presence of genetic diversity between the members of different clusters. Crossing can be made between the members of different clusters as they are genetically diverse. Similar results were observed by Sundaram et al., (2011), Choudhary et al., (2013) and Tomar et al., (2014).

It is concluded that RAPD markers proved best for assessing genetic diversity in fenugreek germplasm. This shows the clear picture of existence of diversity in genotypes at genetic level and the genotypes used in the present study can be utilized for further crop improvement programme.

\section{References}

Balodi, B. and Rao, R. R. (1991), The genus Trigonella L. (Fabaceae) in the Northwest Himalaya. J Econ Tax But, 5(1): 11-16.

Choudhary, S., Meena, R. S., Singh, R., Vishal, M. K., Vibha, C. and Alka, P. (2013), Assessment of genetic diversity among Indian fenugreek (Trigonellafoenum-graecum L.) varieties using morphological and RAPD markers. Legume Res., 36(4): 289-298.

Dangi, R. S., Meena, D. L., Lal, C. B., Prabhakar, R. K. and Vidya, G. S. (2004), Assessment of genetic diversity in Trigonella foenum-graecumand
Trigonella caerulea using ISSR and RAPD markers. BMC Plant Biol., 4(13): 1-10.

Murray, M. G. and Thompson, W. F. (1980), Rapid isolation of high molecular weight plant DNA. Nucleic Acids Research, 8: 4321-4326.

Polhil, R. M. and Raven, P. H. (1981), Advances in legume systematic. Royal Botanical Gardens, Kew, England, 2:23-28.

Saghai-Maroof, M. A., Soliman, K. M., Jorgensen, R. A. and Allard, R. W. (1984), Ribosomal DNA spacer-length polymorphism in Barley: Mendelian inheritance, Chromosomal-location and population dynamics. Proceedings of the National Academy of Sciences, 81: 8014-8019.

Sundaram. S. and Purwar, S. (2011), Assessment of genetic diversity among fenugreek (Trigonella foenum-graecum L.), using RAPD molecular markers. $J$. Med. Plants Res. 5(9): 1543-1548.

Tomar, R. S., Parakhia, M. V., Rathod, V. M., Thakkar, J. R. and Golakiya, B. A. (2014),A Comparative analysis of ISSR and RAPD markers for studying genetic diversity in Trigonella foenumgraecumg enotypes. Res. J. Biotech, 9(10): 89-95.

Williams, J. G. K., Kubelik, A. R., Livak, K. J., Rafalski, J. A. andTingey, S. V. (1990), DNA polymorphisms amplified by arbitrary primers are useful as genetic markers. Nucleic Acids Res., 18, 6531-6535.

\section{How to cite this article:}

Mamatha, N.C., S.K. Tehlan, M. Srikanth, M.K. Shivaprasad and Karthik Reddy, P. 2017. Molecular Characterization of Fenugreek (Trigonellafoenum-graecum L.) Genotypes Using Rapd Markers. Int.J.Curr.Microbiol.App.Sci. 6(6): 2573-2581. doi: https://doi.org/10.20546/ijcmas.2017.606.306 